\title{
Hypersonic Impact Properties of Pristine and Hybrid Single and Multi-layer C3N and BC3 Nanosheets
}

\section{Sadegh Sadeghzadeh ( $\nabla$ sadeghzadeh@iust.ac.ir)}

Iran University of Science and Technology

\section{Kasra Einalipour Eshkalak}

Iran University of Science and Technology

\section{Fatemeh Molaei}

University of Arizona

Hossein Siavoshi

University of Arizona

\section{Research Article}

Keywords: C3N and BC3 nanosheets, C3N-BC3 hybrid, Ballistic properties, Molecular dynamics

Posted Date: December 15th, 2020

DOl: https://doi.org/10.21203/rs.3.rs-118827/v1

License: (c) (i) This work is licensed under a Creative Commons Attribution 4.0 International License.

Read Full License

Version of Record: A version of this preprint was published at Scientific Reports on April 12th, 2021. See the published version at https://doi.org/10.1038/s41598-021-86537-z. 


\title{
Hypersonic impact properties of pristine and hybrid single
}

\author{
and multi-layer $\mathrm{C}_{3} \mathrm{~N}$ and $\mathrm{BC}_{3}$ nanosheets
}

\section{Fatemeh Molaei ${ }^{1}$, Kasra Einalipour Eshkalak ${ }^{2}$, Sadegh Sadeghzadeh ${ }^{3 *}$, Hossein Siavoshi $^{4}$}

1- Ph.D. student, Mining and Geological Engineering Department, The University of Arizona, Arizona, USA

2- Facilities and piping Department, Qazvin Tarom Copper Company and MSc of Nanotechnology Engineering, School of Advanced technologies, Iran University of science and technology, Tehran, Iran

3, *- Associate Professor of Nanotechnology Engineering, School of Advanced Technologies, Iran University of Science and Technology, Tehran, Iran, sadeghzadeh@iust.ac.ir. 4- Graduate student, Mining and Geological Engineering Department, The University of Arizona, Arizona, USA

\begin{abstract}
Two-dimensional (2D) materials are competitive candidates replacing or supplementing conventional semiconductors due to their atomically uniform thickness. To observe and exploit the unique properties of two-dimensional (2D) materials, it is therefore vital to obtain clean and repeatable interfaces. Also, carbon, nitrogen, and boron nanostructures are promising ballistic protection materials due to their low density and excellent mechanical properties. In this study, we evaluated the ballistic properties of $\mathrm{C}_{3} \mathrm{~N}$ and $\mathrm{BC}_{3}$ nanosheets against the hypersonic bullets with Mach number greater than 6 . Besides, we created a hybrid sheet using van der Waals bonds between them based on the hypervelocity impacts of fullerene $\left(\mathrm{C}_{60}\right)$ molecules utilizing molecular dynamics simulation. In the following, the ballistic properties of different structures were examined, and it was shown that $\mathrm{C}_{3} \mathrm{~N}$ nanosheets have higher absorption energy than $\mathrm{BC}_{3}$ after $\mathrm{C}_{60}$ penetration. In contrast, in lower impact speeds and before penetration, singlelayers exhibited almost similar behavior. Our findings also reveal that in hybrid
\end{abstract}


structures, the $\mathrm{C}_{3} \mathrm{~N}$ layers will improve the ballistic properties of $\mathrm{BC}_{3}$. The energy absorption values with a variable number of layers and interlayer distance are investigated, for homogeneous or hybrid configurations (stacking of $\mathrm{C}_{3} \mathrm{~N}$ and $\mathrm{BC}_{3}$ ). In this work, we have discussed two interlayer distances of $\mathrm{X}=3.4 \AA$ and $4 \mathrm{X}=13.6 \AA$ for different configurations. These results provide a fundamental understanding of ultra-light multilayered armors' design using nanocomposites based on advanced 2D materials. It can also be used to select and make 2D membranes and allotropes for DNA sequencing and filtration.

Keywords: $\mathrm{C}_{3} \mathrm{~N}$ and $\mathrm{BC}_{3}$ nanosheets; $\mathrm{C}_{3} \mathrm{~N}-\mathrm{BC}_{3}$ hybrid; Ballistic properties; Molecular dynamics

\section{Introduction}

Two-dimensional materials have been able to revolutionize the use of materials in various fields shortly after their discovery. The interface mediating the connection between nanomaterials and other materials or between themselves is the most important factor and place for new features to emerge ${ }^{1,2}$. Graphene is one of the most significant 2D materials. Utilize a variety of practical problems faced graphene for specific applications. The zero-band characteristic of graphene limits its applications in semiconductors. Two of the known (2D) dielectric materials are polyaniline $\left(\mathrm{C}_{3} \mathrm{~N}\right)$ and $\mathrm{BC}_{3}$. The results show that $\mathrm{C}_{3} \mathrm{~N}$ and $\mathrm{BC}_{3}$ are semiconductors with a band-gap of $0.39 \mathrm{eV}$ and $0.54 \mathrm{eV}$, respectively ${ }^{3,4} \cdot \mathrm{C}_{3} \mathrm{~N}$ is a semiconductor that can be tuned to cover the entire visible range by the fabrication of quantum dots with different diameters ${ }^{5}$. Due to the appearance of new properties and their several applications, 2D hybrid materials have been studied by many researchers ${ }^{6}$. The mechanical properties of pure $\mathrm{BC}_{3}$ and $\mathrm{C}_{3} \mathrm{~N}$ are studied, and details of the results are available under different conditions. 
Mechanical results showed that Young's modulus of $\mathrm{C}_{3} \mathrm{~N}$ is higher than graphene and other $2 \mathrm{D}$ materials ${ }^{7-9}$. So, we can say that $\mathrm{C}_{3} \mathrm{~N}$ and $\mathrm{BC}_{3}$ are excellent candidates for replacement with graphene for different applications. The mechanical properties of $\mathrm{C}_{3} \mathrm{~N}$ sheets without any defects and containing some defects, such as cracks and cavities, were examined. It has also been shown that as the temperature rises from 200 to 900 Kelvin, Young's modulus decreases by $9 \%{ }^{10}$. In 2019, using a simulation of molecular dynamics, Zahedi et al. studied the mechanical properties of $\mathrm{BC}_{3}$ with a focus on defects at different temperatures. The results of this work are compared with $\mathrm{C}_{3} \mathrm{~N}$ and show that the mechanical properties of $\mathrm{C}_{3} \mathrm{~N}$ under the same conditions are higher than $\mathrm{BC}_{3}$ and the higher values of elastic modulus due to stiffening in $\mathrm{C}-\mathrm{N}$ bond compared with $\mathrm{C}-\mathrm{B}$ bond ones ${ }^{11}$. The mechanical and thermal properties of the hybrid of 2D materials are available using molecular dynamics simulation ${ }^{12-19}$. Using the MD technique, in 2013, Zhao et al. examined the mechanical properties of hybrid graphene and hexagonal boron nitride (h-BN) sheet with the concentration of $\mathrm{BN}$, ranging from $0 \%$ to $100 \%$. Irrespective of the form and distribution of BN, Young's modulus of the hybrid sheet decreases with increasing concentration of BN. However, adding a small amount of BN to graphene causes a noticeable drop in the strength of the hybrid sheet ${ }^{12}$. The ballistic properties of 2D materials are of great importance. Protecting structures and devices from the impact of high-energy projectiles is still an open issue for theoretical modeling and applied research. It is also relevant in several technology topics, including materials science and engineering, automotive, aerospace, and defense ${ }^{20}$. Spacecrafts, for instance, are frequently exposed to micrometeoroids and orbital debris hypervelocity collisions (velocities of up to $7-8 \mathrm{~km} / \mathrm{s}$ ). They result in surface degradation, failures on-board instrumentation up to full perforation, and structural damage during operation. In 2017, Signetti et al. studied the ballistic properties of 2D materials due to the high velocity of the collision of a $\mathrm{C}_{60}$ molecule using the DFT and FEM simulation 
methods. The critical penetration energy of graphene membranes and 2D allotropes, including h-BN, has been determined as a case study. In addition, the rules of scalability of energy absorption with the variable number of layers and the distance between the layers have been investigated for homogeneous or hybrid configuration ${ }^{21}$. By combining the finite element method and the molecular dynamics method, Sadeghzadeh and his colleagues were able to model the problem of different particles colliding with graphene plates in a relatively comprehensive way. They showed that the number of layers, aspect ratio, sheet size, interlayer distance, delamination, and projectile shape significantly influence the impact resistance of graphene sheets ${ }^{22}$. In another study, Rafael et al. studied the scale effect on the ballistic penetration of graphene sheets. In this work, a combination of numerical and analytical modeling has been employed to address this issue. They used the reactive molecular dynamics method and examined ballistic tests for single, double, and triple-layered graphene sheets. Their results showed that the specific penetration energy decreases as the number of layers $(\mathrm{N})$ increases, from $\sim 15 \mathrm{MJ} / \mathrm{kg}$ for $\mathrm{N}=1$ to $\sim 0.9 \mathrm{MJ} / \mathrm{kg}$ for $\mathrm{N}=350$, for an impact velocity of $900 \mathrm{~m} / \mathrm{s}^{23}$. The ballistic tests on the two-dimensional materials have also been observed in other works ${ }^{24,25}$.

So far, there have been no reports of the ballistic properties of $\mathrm{BC}_{3}$ and $\mathrm{C}_{3} \mathrm{~N}$ structures. Therefore, due to the unique properties of these two structures and potential applications in various industries, as well as the structural similarity with graphene and the fact that in some properties due to the weakness of graphene can replace graphene in electronic devices, a more detailed study of the ballistic properties of this type of graphene-like structures is essential. Therefore, the ballistic properties of $\mathrm{C}_{3} \mathrm{~N}$ and $\mathrm{BC}_{3}$ were examined using an $\mathrm{MD}$ simulation technique. In different conditions, the elastic properties of the two structures have been studied and compared. The findings show the outstanding mechanical properties of semiconductors $\mathrm{BC}_{3}$ and $\mathrm{C}_{3} \mathrm{~N}$ in full. These features make them 
promising designers and also introduce them to the new catalysts for the design of new nanoelectronics and nanoelectromechanical devices.

\section{Computational Methods}

A large-scale atomic/molecular massively parallel simulator (LAMMPS) was used for simulation ${ }^{26}$. Image processing and analysis are carried out by OVITO visualization software ${ }^{27}$. The interaction between carbon-nitrogen atoms in $\mathrm{C}_{3} \mathrm{~N}$ and carbon-boron in $\mathrm{BC}_{3}$, as well as carbon-carbon in the $\mathrm{C}_{60}$ molecule, has been defined through the Tersoff potential presented by Kinaci et al. ${ }^{28,29}$. However, to investigate the ballistic of these two structures, the optimized potential of interatomic bonds has been used in previous reports ${ }^{30}$. In this potential, the relationship between the energy and the displacement of atoms concerning each other is expressed as:

$$
U_{i j}=f_{c}\left(r_{i j}\right)\left[f_{R}\left(r_{i j}\right)+b_{i j} f_{A}\left(r_{i j}\right)\right]
$$

Function $f_{R}\left(r_{i j}\right)$ indicates the repulsion potential of two particles, e.g., in a nucleus-nucleus interaction, and $f_{A}\left(r_{i j}\right)$ denotes the attraction potential resulting from valence electrons. $b_{i j}$ is a bonding strength term that depends on the local atomic medium surrounding a specific bond, and it is a decreasing function of atoms rearrangement number. $b_{i j}$ contains all the multi-particle effects of potential. These relations express existing functions in these potentials:

$$
f_{R}\left(r_{i j}\right)=-A_{i j} e^{-\lambda_{i j} r_{i j}}, f_{A}\left(r_{i j}\right)=-B_{i j} e^{-\mu_{i j} r_{i j}}
$$




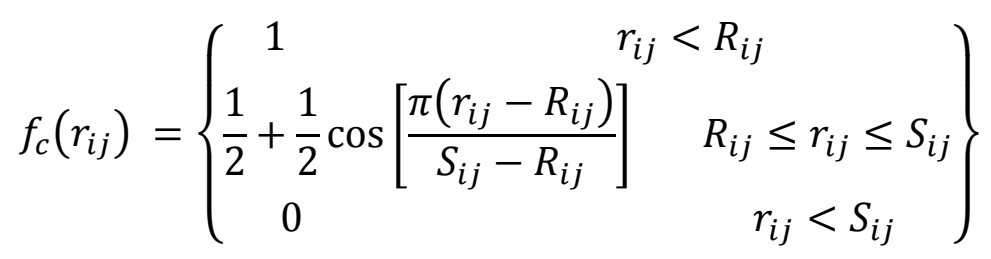

And the required constants are defined as follows:

$$
\begin{aligned}
& b_{i j}=X_{i j}\left(1+B_{i}^{n i} \xi_{i j}^{n i}\right)^{-0.5 n_{i}}, \xi_{i j}=\sum_{k \neq i, j} f_{C}\left(r_{i k}\right) \omega_{i k} g\left(\theta_{i j k}\right) \\
& g\left(\theta_{i j k}\right)=1+\frac{C_{i}{ }^{2}}{d_{i}{ }^{2}}-\frac{C_{i}{ }^{2}}{d_{i}{ }^{2}+\left(h_{i}+\operatorname{Cos} \theta_{i j k}\right)^{2}}, \omega_{i k}=e^{\left[\mu_{i k}{ }^{3}\left(r_{i j-r_{i k}}\right)^{3}\right]} \\
& \lambda_{i j}=\frac{\left(\lambda_{i}+\lambda_{j}\right)}{2}, \mu_{i j}=\frac{\left(\mu_{i}+\mu_{j}\right)}{2}, A_{i j}=\sqrt{A_{i} A_{j}} \\
& B_{i j}=\sqrt{B_{i} B_{j}}, \quad R_{i j}=\sqrt{R_{i} R_{j}}, S_{i j}=\sqrt{S_{i} S_{j}}
\end{aligned}
$$

Indices $\mathrm{i}, \mathrm{j}$, and $\mathrm{k}$ specify the existing atoms in the ijk bond. rij and rik indicate the lengths of $\mathrm{ij}$ and $\mathrm{ik}$ bonds, respectively, with $\theta \mathrm{ijk}$ being the angle between them. These coefficients have been used concerning the coefficients presented above. In the study of ballistic properties, multilayered configurations, which is a nonbonded van der Waals interaction, the Lennard-Jones potential is used. The values of $\varepsilon$ and $\sigma$ can be seen using the following formulas in Table 1 .

$$
\sigma_{i j}=\frac{\sigma_{i}+\sigma_{j}}{2}, \varepsilon_{i j}=\sqrt{\varepsilon_{i} \times \varepsilon_{j}}
$$

Table 1. Lennard-Jones potential coefficients between different atoms in this study

\begin{tabular}{|c|c|c|}
\hline Pair & $\sigma(\AA)$ & $\varepsilon(e V)$ \\
\hline $\mathrm{C}-\mathrm{N}^{31}$ & 3.34577013 & 0.00369113 \\
\hline $\mathrm{C}-\mathrm{B}^{31}$ & 3.53419521 & 0.00596172 \\
\hline $\mathrm{N}-\mathrm{B}^{21}$ & 3.409 & 0.005084 \\
\hline $\mathrm{C}-\mathrm{C}^{32}$ & 3.431 & 0.00455 \\
\hline $\mathrm{B}-\mathrm{B}^{21}$ & 3.453 & 0.004117 \\
\hline $\mathrm{N}-\mathrm{N}^{21}$ & 3.365 & 0.006283 \\
\hline
\end{tabular}

In the present work, the dimensions of the structures $6 \times 6 \mathrm{~nm} 2$ are considered. The total number of atoms present in the simulation is 1404 , the share of carbon atoms is 1068 (Contains 60 carbon atoms for the fullerene molecule), and the total share of boron and nitrogen atoms in $\mathrm{BC}_{3}$ and $\mathrm{C}_{3} \mathrm{~N}$ structures is 336 (Figure 1). Periodic 
boundary conditions were applied in all three directions. After generating the ensemble of random velocity at $300 \mathrm{~K}$, the system runs to reach out to equilibrium at $300 \mathrm{~K}$ under the isothermal-isobaric (NPT) ensemble with the Nose-Hoover thermostat. The time step is 0.25 fs for $50 \mathrm{ps}$, and the velocity Verlet algorithm was used to integrate the Hamiltonian equations of the determined motion. After equilibrium, the ballistic properties are investigated by throwing a fixed-speed fullerene molecule toward $\mathrm{C}_{3} \mathrm{~N}$ and $\mathrm{BC}_{3}$. One row of atoms at the boundary of the structure was fixed in both $\mathrm{x}$ and $\mathrm{y}$ directions. Consequently, the nanosheets maintained their equilibrium when they collided with the fullerene molecule. The distance between the $\mathrm{C}_{60}$ molecule and the surface of the nanosheets is considered to be $5 \mathrm{~nm}$.
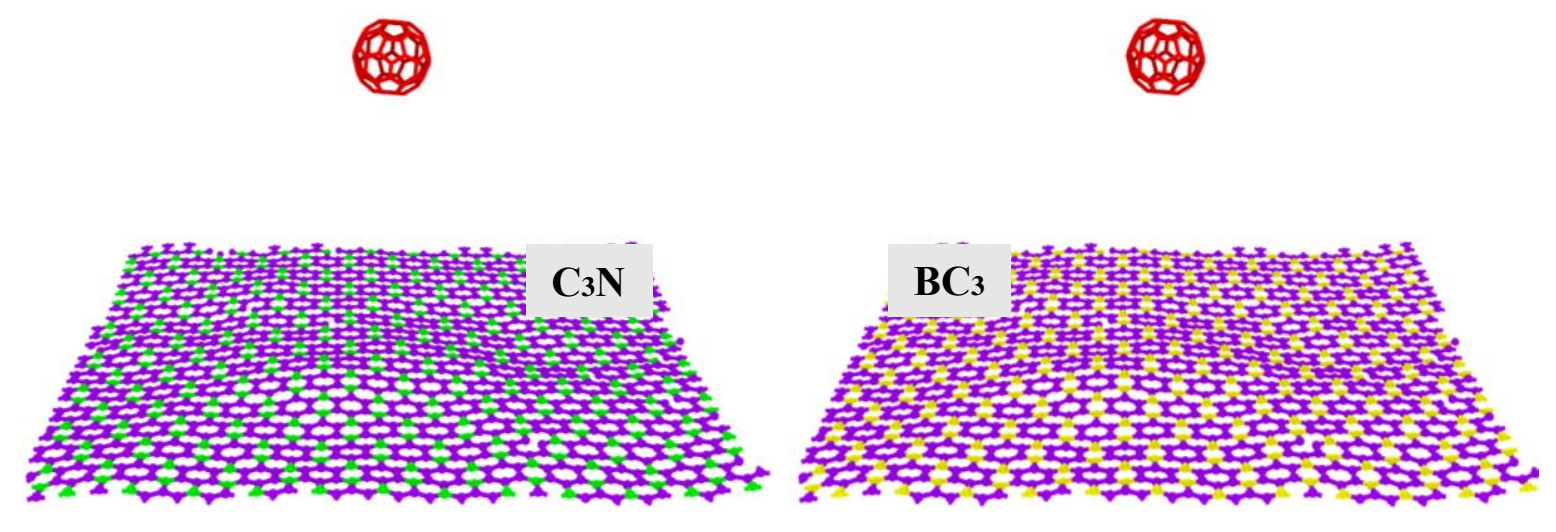

Figure 1. The $\mathrm{C}_{3} \mathrm{~N}$ (left) and $\mathrm{BC}_{3}$ (right) atomic configuration with a honeycomb structure includes carbon-nitrogen and carbon-boron atoms, respectively. The red bonds show the structure of the fullerene molecule. In their ideal structures, each boron and nitrogen atom is surrounded by three carbon atoms. Carbon, nitrogen, and boron atoms are presented respectively in purple, green, and yellow.

To better understand the stress distribution in the present work, after computing the stress tensor on each atom, the equivalent stress of a sheet is calculated based on Von Mises stress. 


$$
\sigma_{V-M}=\sqrt{\frac{1}{2}\left[\left(\sigma_{11}-\sigma_{22}\right)+\left(\sigma_{11}-\sigma_{33}\right)+\left(\sigma_{22}-\sigma_{33}\right)+6\left(\sigma^{2}{ }_{12}+\sigma_{23}^{2}+\sigma^{2}{ }_{31}\right)\right.}
$$

That $\sigma_{1,2,3}$ represents the stress in three directions $\mathrm{x}, \mathrm{y}$, and $\mathrm{z}$.

\section{Results and discussion}

\subsection{Ballistic properties}

For vertical stacks of two-dimensional materials, the layers are placed side-byside with the van der Waals interaction. At the nanoscale, a synergistic interaction occurs between the layers, which is not observed at the micro and macro scales. Several desirable layers, between 5 and 10 layers, indicate that a multilayer twodimensional material has an impact force even higher than its single-layer counterparts. These results provide a basic insight into the design of ultra-light multi-layered armor using nanocomposites based on advanced 2D materials. In a variety of other applications in the electronics field, impact assessment is of significant importance, which can cause unintended and severe shocks during use. Protection with a massive shield is undoubtedly obvious, but it is often impossible because lightness, flexibility, or ergonomics are of particular importance in all of these applications. Therefore, more and more attention has been paid to the development of unconventional nanocomposites with specific toughness and low weight ${ }^{21}$.

Thus, in this section, the single-layer and multilayer ballistic properties of $\mathrm{C}_{3} \mathrm{~N}$ and $\mathrm{BC}_{3}$, including a hybrid of both nanosheets, have been investigated. $\mathrm{A}_{60}$ molecule is thrown at different speeds towards the two-dimensional nanosheets studied in the present work. Drawing the residual velocity curve of the projectile $\left(\mathrm{V}_{\text {res }}\right)$ against the initial velocity value of impact $\left(\mathrm{V}_{0}\right)$ is a common method for ballistic analysis to compare the response of different thin armor due to impact 
(Figure 2). This diagram is known as the ballistic curve, which easily enables us to differentiate between projectile and penetration regimes so that critical penetration energy can be detected.

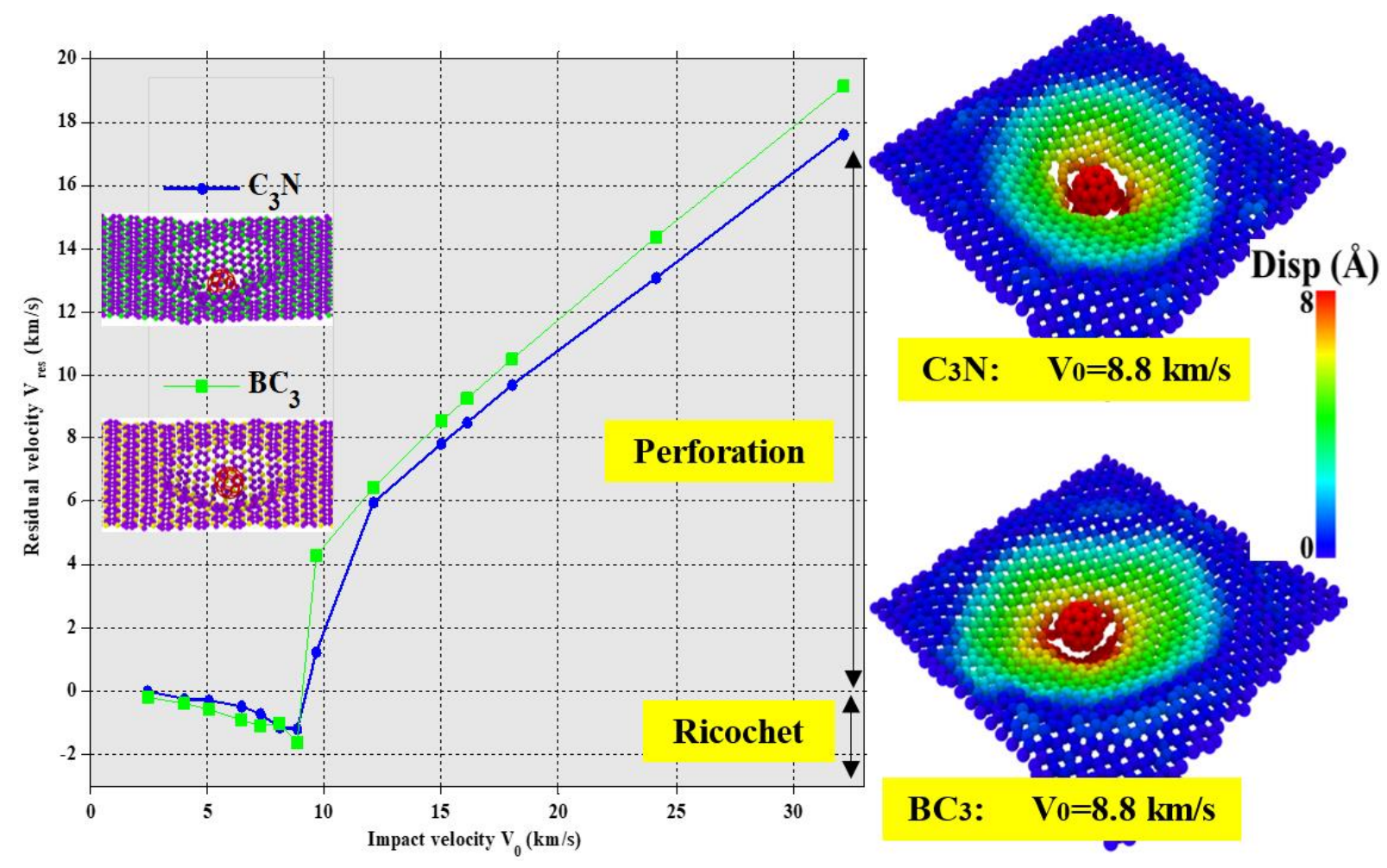

Figure 2. Left panel: Ballistic curves of single layer $\mathrm{C}_{3} \mathrm{~N}$ and $\mathrm{BC}_{3}$. The residual velocity

$\mathrm{V}_{\text {res }}$ is referred to the average velocity of the $\mathrm{C}_{60}$ atoms in the $\mathrm{Z}$ direction. Right panel:

Configurations of $\mathrm{C}_{3} \mathrm{~N}$ and $\mathrm{BC}_{3}$ at the $8.8 \mathrm{~km} / \mathrm{s}$ initial velocity of $\mathrm{C}_{60}$ with MD simulation. The color of each atom indicates its displacement. For visual clarity, the color bar is limited up to $8 \AA$, and the same color shows all displacements beyond this point.

In this work, we have considered the initial velocity of the $\mathrm{C}_{60}$ molecule from 2.45 to $64.27 \mathrm{~km} / \mathrm{s}$ in fifteen different values. The projectile's initial and secondary velocity and kinetic energy values can be seen accurately in Table 2. It is clear that $\mathrm{C}_{3} \mathrm{~N}$ provides higher penetration velocity and impact energy than single layer $\mathrm{BC}_{3}$. As a result, $\mathrm{C}_{3} \mathrm{~N}$ has a lower residual velocity after perforation but shows an almost equal restitution coefficient in the ricochet regime compared to $\mathrm{BC}_{3}$. 
Table 2. Comparison of Residual Kinetic Energy $\left(\mathrm{K}_{\text {res }}\right)$ and Velocity $\left(\mathrm{V}_{\text {res }}\right)$ of monolayer $\mathrm{C} 3 \mathrm{~N}, \mathrm{BC} 3$ using molecular dynamics simulations (present study) and Kres and Vres of graphene, h-BN using DFT and FEM (Previous Reports).

\begin{tabular}{|c|c|c|c|c|c|c|}
\hline \multirow{17}{*}{ 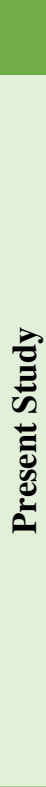 } & & & \multicolumn{2}{|c|}{$\mathbf{C}_{3} \mathbf{N}$} & \multicolumn{2}{|c|}{$\mathbf{B C}_{3}$} \\
\hline & $\mathbf{K}_{0}(\mathbf{e V})$ & $\mathrm{V}_{\mathbf{0}}(\mathbf{k m} / \mathbf{s})$ & $\mathbf{K}_{\text {res }}(\mathbf{e V})$ & $\mathbf{V}_{\text {res }}(\mathbf{k m} / \mathbf{s})$ & $\mathbf{K}_{\text {res }}(\mathbf{e V})$ & $\mathbf{V}_{\text {res }}(\mathbf{k m} / \mathbf{s})$ \\
\hline & 23.3 & 2.45 & 0 & 0 & -0.17 & -0.21 \\
\hline & 61.12 & 4.05 & -0.24 & -0.25 & -0.54 & -0.38 \\
\hline & 96.82 & 5.1 & -0.36 & -0.31 & -1.21 & -0.57 \\
\hline & 155.51 & 6.46 & -0.94 & -0.5 & -3.09 & -0.91 \\
\hline & 196.63 & 7.27 & -1.99 & -0.73 & -4.43 & -1.09 \\
\hline & 242.39 & 8.07 & -5.19 & -1.18 & -3.96 & -1.03 \\
\hline & 293.2 & 8.87 & -5.37 & -1.2 & -10.15 & -1.65 \\
\hline & 348.75 & 9.68 & 5.64 & 1.23 & 68.27 & 4.28 \\
\hline & 543.8 & 12.08 & 133.27 & 5.98 & 154.08 & 6.43 \\
\hline & 835.13 & 14.97 & 228 & 7.822 & 273.76 & 8.571 \\
\hline & 955.2 & 16.1 & 269.25 & 8.5 & 320.24 & 9.27 \\
\hline & 1207.41 & 18 & 349.2 & 9.68 & 411.63 & 10.51 \\
\hline & 2169.83 & 24.13 & 640.5 & 13.11 & 769.53 & 14.37 \\
\hline & 3851.88 & 32.15 & 1156.98 & 17.62 & 1370.92 & 19.18 \\
\hline & 15393.18 & 64.27 & 5190.34 & 37.32 & 5962.55 & 40 \\
\hline & & & \multicolumn{2}{|c|}{ Graphene 21} & \multicolumn{2}{|c|}{ h-BN ${ }^{21}$} \\
\hline \multirow{10}{*}{ 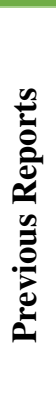 } & 33.63 & 3.0 & -1.30 & -0.059 & -0.03 & -0.09 \\
\hline & 59.78 & 4.0 & -2.47 & -0.81 & -0.14 & -0.19 \\
\hline & 93.41 & 5.0 & -4.30 & -1.07 & -2.00 & -0.73 \\
\hline & 134.51 & 6.0 & -6.43 & -1.31 & -4.83 & -1.14 \\
\hline & 183.09 & 7.0 & -8.41 & -1.50 & -5.37 & -1.20 \\
\hline & 209.88 & 7.5 & -8.07 & -1.47 & 0.00 & 0.00 \\
\hline & 239.13 & 8.0 & -7.52 & -1.42 & 9.42 & 1.59 \\
\hline & 302.65 & 9.0 & -4.60 & -1.11 & 51.15 & 3.70 \\
\hline & 336.73 & 9.5 & 0.000 .00 & 0.00 & 79.06 & 4.60 \\
\hline & 373.64 & 10.0 & 11.15 & 1.73 & 113.85 & 5.52 \\
\hline
\end{tabular}

The restitution coefficient was calculated and plotted in figure 3 versus impact velocity. As could be observed, increasing the impact velocity, the restitution coefficient increases gradually. The variation of the restitution coefficient of $\mathrm{BC}_{3}$ is more limited concerning the coefficient of $\mathrm{C}_{3} \mathrm{~N}$ sheets. 


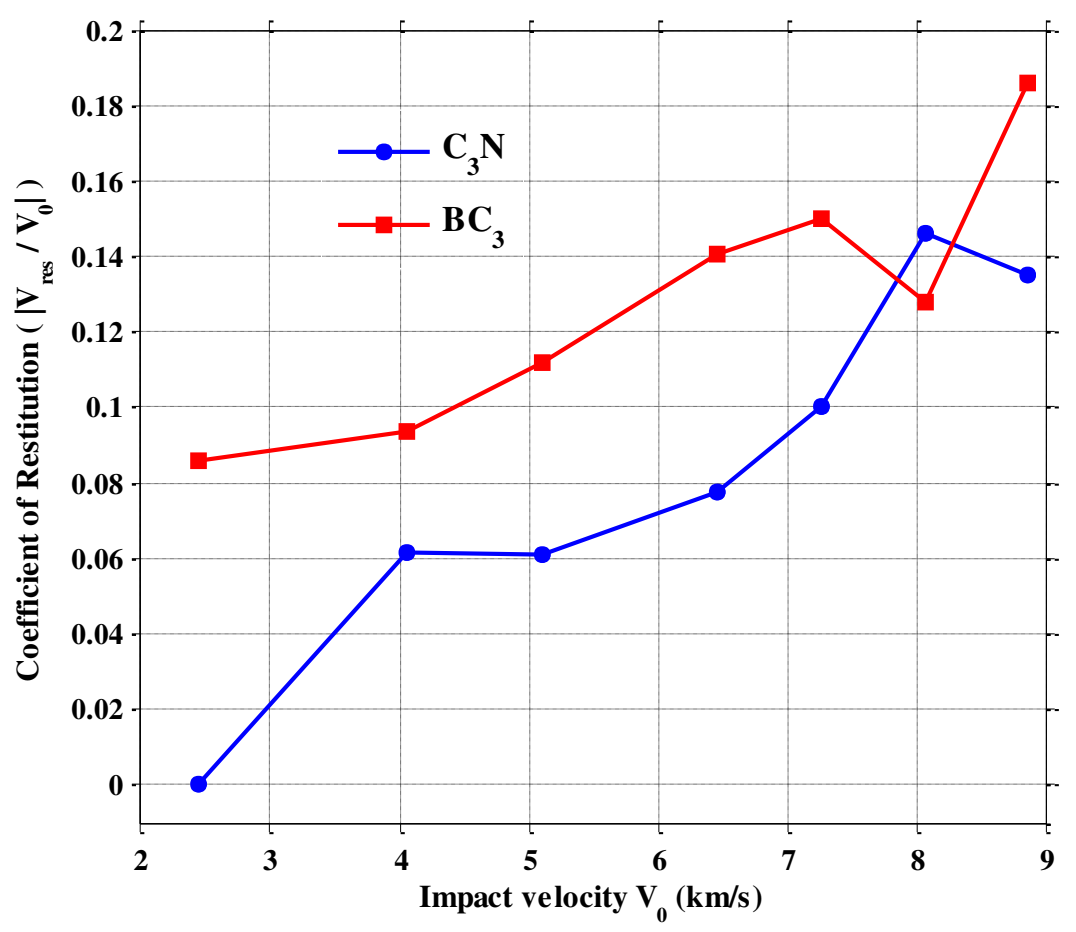

Figure 3. Coefficient of restitution for the collision of a $\mathrm{C}_{60}$ molecule along the zdirection

From these results, it is clear that $\mathrm{BC}_{3}$ sheets absorb more energy from carbon projectiles than $\mathrm{C}_{3} \mathrm{~N}$ sheets. From another point of view, perhaps this difference can be related to the natural frequency of oscillations of these two sheets. The natural frequency of the $\mathrm{BC}_{3}$ sheet is higher than that of the $\mathrm{C}_{3} \mathrm{~N}$ sheet due to its higher flexural strength and therefore better absorbs high-velocity bullets. Because when a bullet or projectile approaches its surface, the atoms of these sheets show the possibility of faster displacements due to the higher frequency in response to the presence of the bullet. This issue can be investigated in future studies by studying the free vibrations of these sheets.

The increasing number of layers for the two interlayer distance modes, including $\mathrm{d}=\mathrm{X}=0.34 \mathrm{~nm}$ and $\mathrm{d}=4 \mathrm{X}=1.36 \mathrm{~nm}$ on ballistic properties, has been discussed. Therefore, the $\mathrm{C}_{3} \mathrm{~N}$ and $\mathrm{BC}_{3}$ multilayer structures and the hybrid of these two sheets are constructed in the form of van der Waals bonds. The $\mathrm{C}_{60}$ molecule is thrown towards desired structures with $\mathrm{V}_{0}=64.27 \mathrm{~km} / \mathrm{s}$ and $\mathrm{K}_{0}=24.66 \times 10^{-16} \mathrm{~J}$. 
The simulation process in this section for the 4-layer model is delineated in both $\mathrm{d}=\mathrm{X}$ and $\mathrm{d}=4 \mathrm{X}$ interlayer distances in Figure 4.
$\mathbf{C}_{3} \mathbf{N}$
$\mathrm{BC}_{3}$
Hybrid
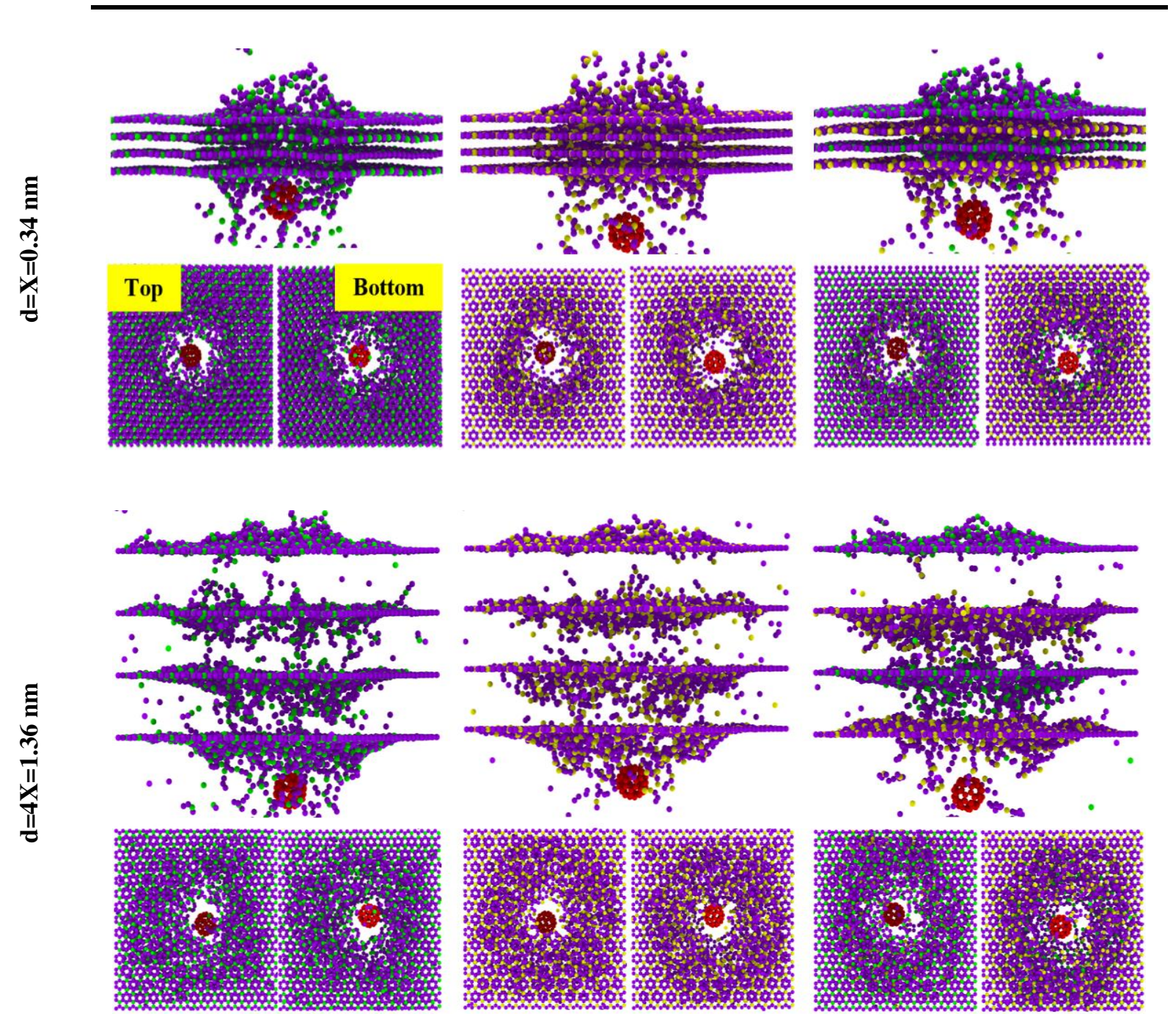

Figure 4. Image of configurations created after the $\mathrm{C}_{60}$ impact on four-layer stacks of the $\mathrm{C}_{3} \mathrm{~N}, \mathrm{BC}_{3}$, and $\mathrm{C}_{3} \mathrm{~N}-\mathrm{BC}_{3}$ hybrid nanosheets with $\mathrm{K}_{0}=15393.19 \mathrm{eV}$ for different layer spacing including $\mathrm{d}=\mathrm{X}=0.34$ and $\mathrm{d}=4 \mathrm{X}=1.36 \mathrm{~nm}$.

The kinetic energy of all states after impact is shown in Figure 5. It is entirely evident that $\mathrm{C}_{3} \mathrm{~N}$ nanosheets absorb more energy from the $\mathrm{C}_{60}$ molecule due to their strong $\mathrm{C}-\mathrm{N}$ bond, and even when it combines with the $\mathrm{BC}_{3}$ sheet, they can increase its ballistic properties and reduce the kinetic energy of fullerenes further. It is important to note that as the interlayer distance increases from $\mathrm{d}=\mathrm{X}$ to $\mathrm{d}=4 \mathrm{X}$, 
the amount of kinetic energy decreases significantly. For example, when the interlayer distance is $\mathrm{d}=4 \mathrm{X}$, the kinetic energy of $\mathrm{C}_{60}$ is 27 percent lower than when the interlayer distance is $d=X$. As the distance between layers increases, the removed carbon and nitrogen atoms (for example, in $\mathrm{C}_{3} \mathrm{~N}$ ) from the first sheet have more space and do not extend along with the $\mathrm{C}_{60}$ molecule's motion. When the surface separation from the first layer hits the sides of the second layer, it does not smooth the path of the $\mathrm{C}_{60}$ molecule and only causes more damage to the next layers in the whole sheet. However, this does not happen for shorter interlayer distances. As soon as the atoms separate from the first layer, they quickly hit the second layer, and the path of the projectile molecule will be smoother. Therefore, it can be concluded that although increasing the interlayer distance between $2 \mathrm{D}$ materials improves the ballistic properties, on the other hand, it causes irreparable damage to the next layers. So, it is not able to withstand excessive pressures for use and application in two-dimensional membranes and purification applications.
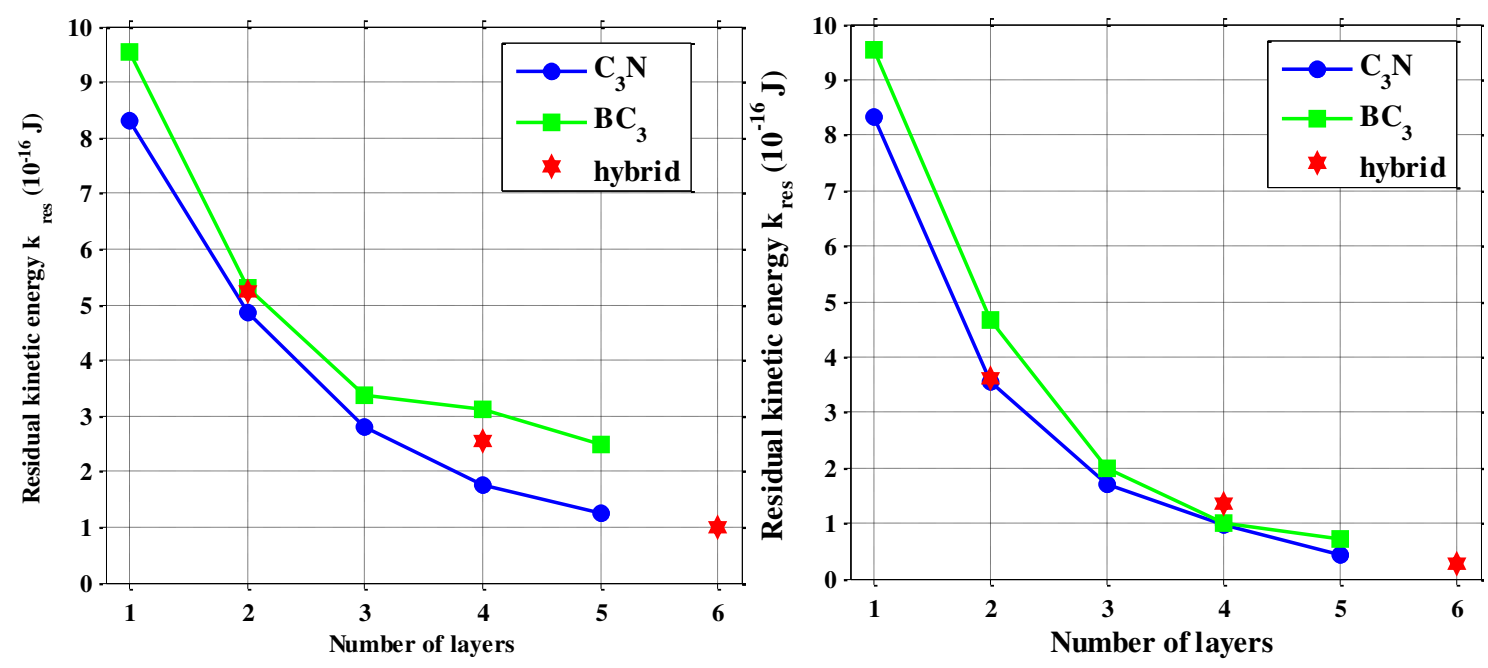

Figure 5. The number of layers effect on the residual kinetic energy Kres in the C3N, $\mathrm{BC} 3$, and $\mathrm{C} 3 \mathrm{~N}-\mathrm{BC} 3$ hybrid nanosheets with $\mathrm{K} 0=24.66 \times 10-16 \mathrm{~J}$ for different layer spacing including $\mathrm{d}=\mathrm{X}=0.34$ and $\mathrm{d}=4 \mathrm{X}=1.36 \mathrm{~nm}$.

Due to the thin nature of the two-dimensional material, these materials may easily 
deform out-of-plane by arc or wrinkle automatically on the substrates. Although these out-of-plane alterations are very small in size (below the Angstrom scale), nevertheless, they significantly change the effective properties. For example, outof-plane wrinkles may reduce Young's modulus of the single-layer, but increase toughness or chemical activity ${ }^{33}$. In the present study, an attempt has been made to remove wrinkles. However, just in the case of $\mathrm{C}_{3} \mathrm{~N}$ and $\mathrm{BC}_{3}$ combination with a $\mathrm{d}=4 \mathrm{X}$ layered distance and due to strong van der Waals interaction and prevailing physical and chemical interactions between these two layers, $\mathrm{BC}_{3}$ structure towards one layer $\mathrm{C}_{3} \mathrm{Ns}$ is stretched from top to bottom and causes buckling in the system. This stretch can ultimately have little effect on the results. In many studies, the single-layer thickness of graphene is assumed to be $0.334 \mathrm{~nm}$, while measurements using an atomic force microscope (AFM) report this value from 0.4 to $1.7 \mathrm{~nm}^{34}$. Another important parameter in elastic properties is the amount of energy absorbed by two-dimensional materials, which is obtained by calculating $\left|\mathrm{V}_{0}^{2}-\mathrm{V}_{\text {res }}{ }^{2}\right| / \mathrm{V}_{0}{ }^{2}$. Therefore, Figure 6 shows absorbed energy changes by increasing impact velocity and increasing the number of layers for $\mathrm{C}_{3} \mathrm{~N}, \mathrm{BC}_{3}$, and hybrid structures.
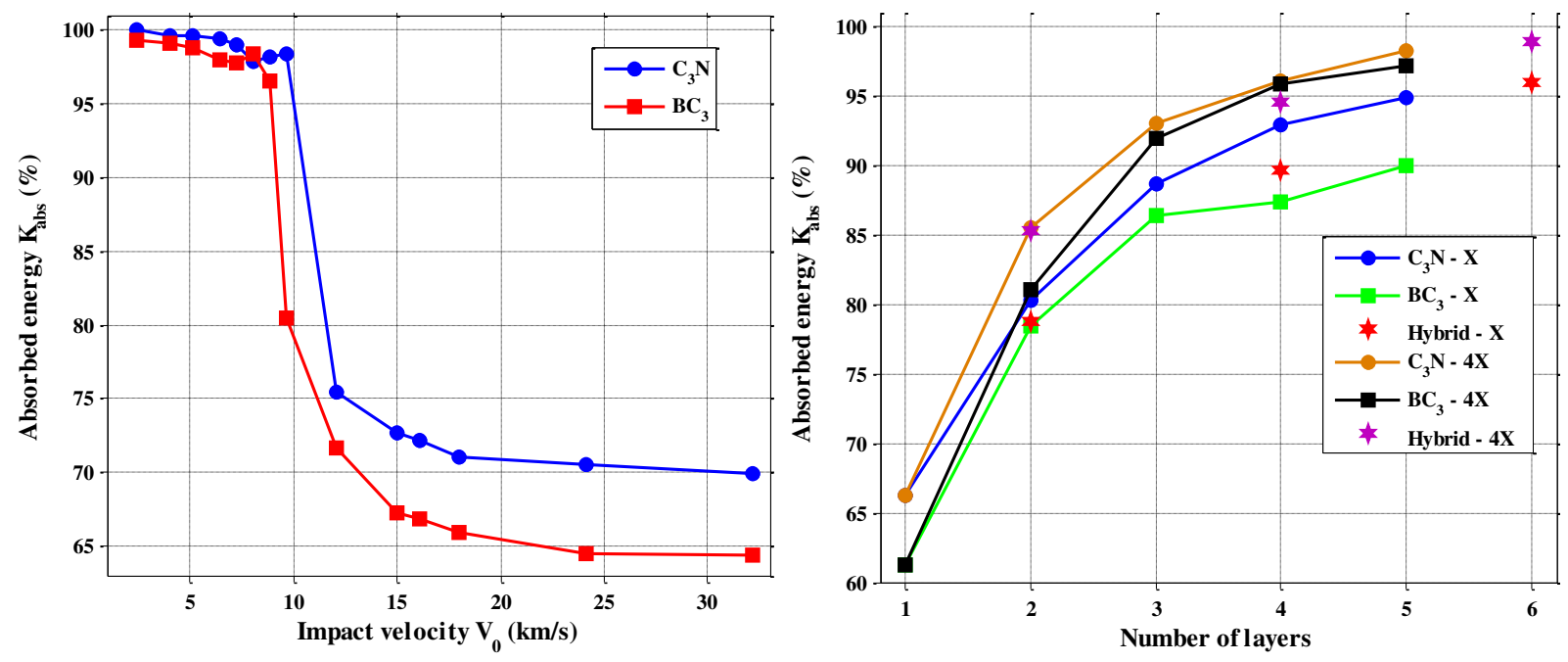

Figure 6. The energy changes adsorbed by the left sheet: increasing impact velocity and right panel: the increasing number of layers for $\mathrm{C}_{3} \mathrm{~N}, \mathrm{BC}_{3}$, and their hybrid structures. 
To better understand the behavior of stress distribution in different systems after the $\mathrm{C}_{60}$ penetration, we obtained the von Mises stress of single-layer and three samples of four-layer structure for $d=X$ and $d=4 X$ layered spacing, which is depicted in Figure 7. The results show that the stress distribution is different in several modes. The nitrogen and boron atoms do not have the same behavior at different interlayer distances, and this is related to the distribution of stress in the structures. It has been observed that $\mathrm{C}_{3} \mathrm{~N}$ has better performance in stress distribution and distributed maximum stresses uniformly throughout the monolayer sheet. Thus, the stress concentration in this structure has been lower than the others; it will have better mechanical and ballistic properties. 


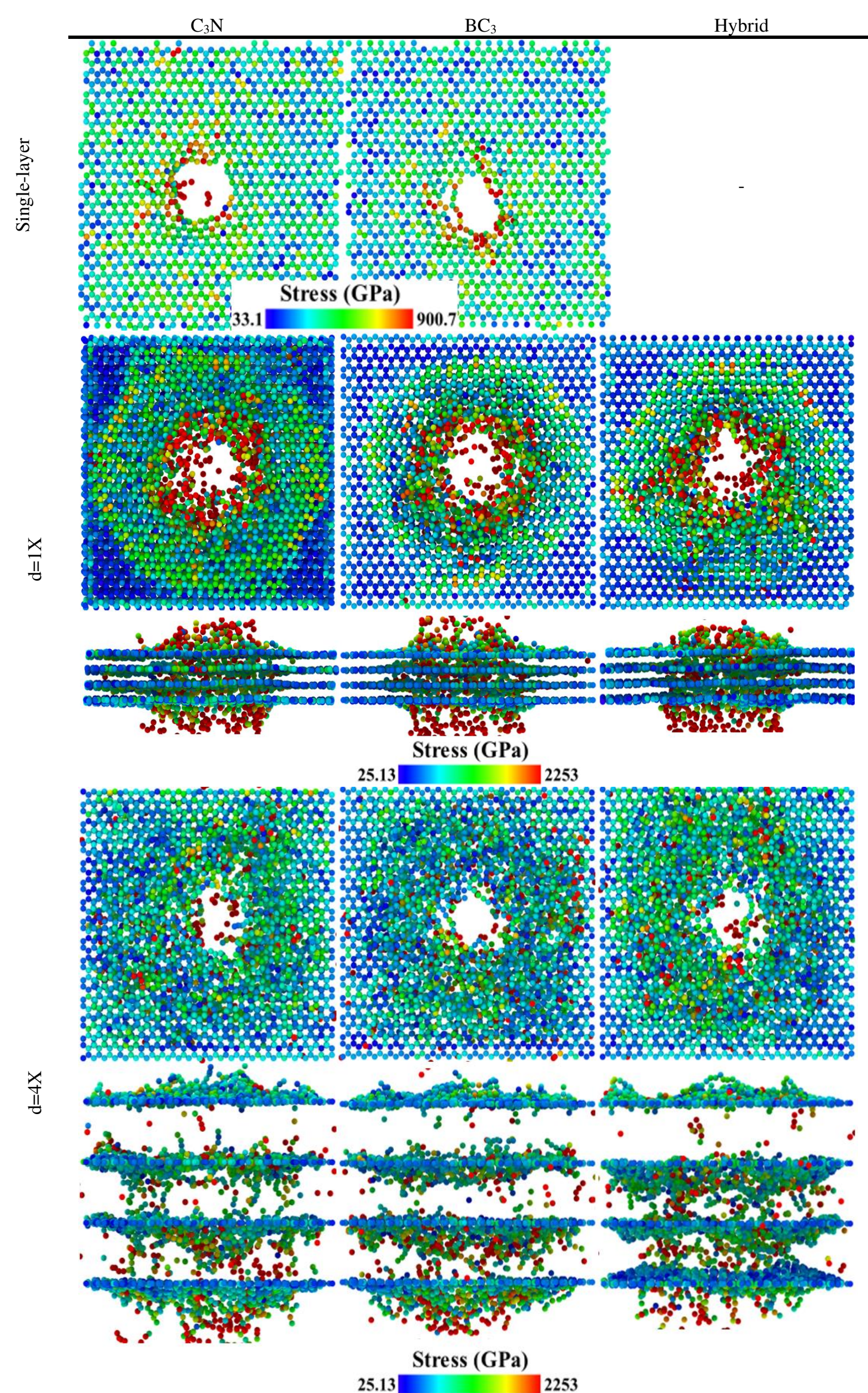

Figure 7. Von Mises stress distribution on a single layer and four-layer stacks of the $\mathrm{C}_{3} \mathrm{~N}, \mathrm{BC}_{3}$, and $\mathrm{C}_{3} \mathrm{~N}-\mathrm{BC}_{3}$ hybrid nanosheets after the $\mathrm{C}_{60}$ impact with $\mathrm{V}_{0}=64.27 \mathrm{~km} / \mathrm{s}$ for different layer spacing including $\mathrm{X}=0.34$ and $4 \mathrm{X}=1.36 \mathrm{~nm}$. 


\section{Conclusions}

In this work, we studied the ballistic behavior of single and multi-layered armor $\mathrm{C}_{3} \mathrm{~N}$ and $\mathrm{BC}_{3}$ and their hybrid, which is exposed to the impact of a high-speed $\mathrm{C}_{60}$ molecule by using molecular dynamics simulation techniques. Our results indicated that the speed and energy of the $\mathrm{C}_{60}$ molecule dropped sharply after hitting the single layers, which shows the high absorption energy of these two structures. Meanwhile, the absorption energy of $\mathrm{C}_{3} \mathrm{~N}$ is higher than $\mathrm{BC}_{3}$ and is enhanced the absorption power of $\mathrm{BC}_{3}$, even in hybrid systems. In this work, we have introduced the interlayer distance as one of the effective parameters in ballistic properties and showed that when this distance changes from $\mathrm{d}=\mathrm{X}=0.34$ $\mathrm{nm}$ to $\mathrm{d}=4 \mathrm{X}=1.36 \mathrm{~nm}$ : for example, in two-layer $\mathrm{C}_{3} \mathrm{~N}$, the kinetic energy of the $\mathrm{C}_{60}$ for the $4 \mathrm{X}$ interlayer After the collision is calculated to be $27 \%$ less than the $\mathrm{d}=\mathrm{X}$ distance. However, the damage caused by the increase in the interlayer distance for the single layers is also predictable after the $\mathrm{C}_{60}$ molecule hits the first sheet. To this end, in the present study, the von Mises stress distribution behavior has been analyzed to create two-dimensional nanoparticles composed of $\mathrm{C}_{3} \mathrm{~N}$ and $\mathrm{BC}_{3}$. Therefore, the $\mathrm{C}_{3} \mathrm{~N}$ structure has a better stress distribution than $\mathrm{BC}_{3}$.

\section{References}

1 Rosenberger, M. R. et al. Nano-"Squeegee" for the Creation of Clean 2D Material Interfaces. ACS Applied Materials \& Interfaces 10, 10379-10387, doi:10.1021/acsami.8b01224 (2018).

2 Eshkalak, K. E., Sadeghzadeh, S. \& Jalaly, M. Thermal resistance analysis of hybrid grapheneboron nitride nanosheets: The effect of geometry, temperature, size, strain and structural defects. Computational Materials Science 174, 109484, doi:https://doi.org/10.1016/j.commatsci.2019.109484 (2020).

3 Chigo-Anota, E., Alejandro, M. A., Hernández, A. B., Torres, J. J. S. \& Castro, M. Long range corrected-wPBE based analysis of the $\mathrm{H} 2 \mathrm{O}$ adsorption on magnetic $\mathrm{BC} 3$ nanosheets. RSC Advances 6, 20409-20421, doi:10.1039/C5RA27231A (2016).

4 Siwei, Y. et al. C3N-A 2D Crystalline, Hole-Free, Tunable-Narrow-Bandgap Semiconductor with Ferromagnetic Properties. Advanced Materials 29, 1605625, doi:doi:10.1002/adma.201605625 (2017). 
5 Yang, S. et al. C3N-A 2D Crystalline, Hole-Free, Tunable-Narrow-Bandgap Semiconductor with Ferromagnetic Properties. Advanced Materials 29, 1605625 (2017).

$6 \quad$ Wu, Q. et al. In situ chemical vapor deposition of graphene and hexagonal boron nitride heterostructures. Current Applied Physics 16, 1175-1191, doi:https://doi.org/10.1016/j.cap.2016.04.024 (2016).

7 Mortazavi, B. Ultra high stiffness and thermal conductivity of graphene like C3N. Carbon 118, 25-34, doi:https://doi.org/10.1016/j.carbon.2017.03.029 (2017).

8 Sadeghzadeh, S. Effects of vacancies and divacancies on the failure of C3N nanosheets. Diamond Relat. Mater. 89, 257-265, doi:https://doi.org/10.1016/j.diamond.2018.09.018 (2018).

9 Mortazavi, B. et al. Outstanding strength, optical characteristics and thermal conductivity of graphene-like BC3 and BC6N semiconductors. Carbon 149, 733-742, doi:https://doi.org/10.1016/j.carbon.2019.04.084 (2019).

10 Shirazi, A. H. N., Abadi, R., Izadifar, M., Alajlan, N. \& Rabczuk, T. Mechanical responses of pristine and defective $\mathrm{C} 3 \mathrm{~N}$ nanosheets studied by molecular dynamics simulations.

Computational Materials Science 147, 316-321, doi:https://doi.org/10.1016/j.commatsci.2018.01.058 (2018).

11 Zahedi, R. K., Shirazi, A. H. N., Alimouri, P., Alajlan, N. \& Rabczuk, T. Mechanical properties of graphene-like BC3; a molecular dynamics study. Computational Materials Science 168, 1-10, doi:https://doi.org/10.1016/j.commatsci.2019.05.053 (2019).

12 Zhao, S. \& Xue, J. Mechanical properties of hybrid graphene and hexagonal boron nitride sheets as revealed by molecular dynamic simulations. Journal of Physics D: Applied Physics 46, 135303, doi:10.1088/0022-3727/46/13/135303 (2013).

13 Ding, N., Chen, X. \& Wu, C.-M. L. Mechanical properties and failure behaviors of the interface of hybrid graphene/hexagonal boron nitride sheets. Scientific Reports 6, 31499, doi:10.1038/srep31499

https://www.nature.com/articles/srep31499\#supplementary-information (2016).

14 Einalipour Eshkalak, K., Sadeghzadeh, S. \& Jalaly, M. The mechanical design of hybrid graphene/boron nitride nanotransistors: Geometry and interface effects. Solid State Commun. 270, 82-86, doi:https://doi.org/10.1016/j.ssc.2017.12.001 (2018).

15 Eshkalak, K. E., Sadeghzadeh, S. \& Jalaly, M. Mechanical properties of defective hybrid graphene-boron nitride nanosheets: A molecular dynamics study. Computational Materials Science 149, 170-181 (2018).

16 Eshkalak, K. E., Sadeghzadeh, S. \& Jalaly, M. Studying the effects of longitudinal and transverse defects on the failure of hybrid graphene-boron nitride sheets: A molecular dynamics simulation. Physica E: Low-dimensional Systems and Nanostructures 104, 71-81 (2018). 
17 Einalipour Eshkalak, K., Sadeghzadeh, S. \& Molaei, F. Interfacial Thermal Resistance Mechanism for Polyaniline (C3N)-Graphene Heterostructure. The Journal of Physical Chemistry C, doi:10.1021/acs.jpcc.0c02051 (2020).

18 Tafrishi, H., Sadeghzadeh, S., Molaei, F. \& Siavoshi, H. Investigating the effects of adding hybrid nanoparticles, graphene and boron nitride nanosheets, to octadecane on its thermal properties. RSC Advances 10, 14785-14793, doi:10.1039/DORA01847C (2020).

19 Tafrishi, H. et al. Investigation of tetracosane thermal transport in presence of graphene and carbon nanotube fillers-A molecular dynamics study. Journal of Energy Storage 29, 101321, doi:https://doi.org/10.1016/j.est.2020.101321 (2020).

20 Eshkalak, K. E., Sadeghzadeh, S. \& Molaei, F. Aluminum nanocomposites reinforced with monolayer polyaniline (C3N): assessing the mechanical and ballistic properties. RSC Advances 10, 19134-19148, doi:10.1039/DORA03204B (2020).

21 Signetti, S., Taioli, S. \& Pugno, N. M. 2D Material Armors Showing Superior Impact Strength of Few Layers. ACS Applied Materials \& Interfaces 9, 40820-40830, doi:10.1021/acsami.7b12030 (2017).

22 Sadeghzadeh, S. Computational design of graphene sheets for withstanding the impact of ultrafast projectiles. J. Mol. Graph. Model. 70, 196-211 (2016).

23 Bizao, R. A., Machado, L. D., de Sousa, J. M., Pugno, N. M. \& Galvao, D. S. Scale Effects on the Ballistic Penetration of Graphene Sheets. Scientific Reports 8, 6750, doi:10.1038/s41598-01825050-2 (2018).

24 Baringhaus, J. et al. Exceptional ballistic transport in epitaxial graphene nanoribbons. Nature 506, 349-354, doi:10.1038/nature12952 (2014).

25 Lee, J.-H., Loya, P. E., Lou, J. \& Thomas, E. L. Dynamic mechanical behavior of multilayer graphene via supersonic projectile penetration. Science 346, 1092-1096, doi:10.1126/science.1258544 (2014).

26 Plimpton, S. Fast parallel algorithms for short-range molecular dynamics. (United States, 1993).

27 Stukowski, A. Visualization and analysis of atomistic simulation data with OVITO-the Open Visualization Tool. Modelling and Simulation in Materials Science and Engineering 18, 015012, doi:10.1088/0965-0393/18/1/015012 (2009).

28 Lindsay, L. \& Broido, D. A. Optimized Tersoff and Brenner empirical potential parameters for lattice dynamics and phonon thermal transport in carbon nanotubes and graphene. Physical Review B 81, 205441, doi:10.1103/PhysRevB.81.205441 (2010).

29 Kınacı, A., Haskins, J. B., Sevik, C. \& Çağın, T. Thermal conductivity of BN-C nanostructures. Physical Review B 86, 115410, doi:10.1103/PhysRevB.86.115410 (2012).

30 Zhang, Y.-Y., Pei, Q.-X., Sha, Z.-D. \& Zhang, Y.-W. A molecular dynamics study of the mechanical properties of $\mathrm{h}-\mathrm{BCN}$ monolayer using a modified Tersoff interatomic potential. Physics Letters A 383, 2821-2827, doi:https://doi.org/10.1016/j.physleta.2019.05.055 (2019). 
31 Abadi, R., Nezhad Shirazi, A. H., Izadifar, M., Sepahi, M. \& Rabczuk, T. Fabrication of nanopores in polycrystalline boron-nitride nanosheet by using $\mathrm{Si}$, SiC and diamond clusters bombardment. Computational Materials Science 145, 280-290, doi:https://doi.org/10.1016/j.commatsci.2017.12.022 (2018).

32 Inui, N. \& Iwasaki, S. Interaction Energy between Graphene and a Silicon Substrate Using Pairwise Summation of the Lennard-Jones Potential. e-Journal of Surface Science and Nanotechnology 15, 40-49, doi:10.1380/ejssnt.2017.40 (2017).

33 Androulidakis, C., Zhang, K., Robertson, M. \& Tawfick, S. Tailoring the mechanical properties of 2D materials and heterostructures. 2D Materials 5, 032005, doi:10.1088/20531583/aac764 (2018).

34 Shearer, C. J., Slattery, A. D., Stapleton, A. J., Shapter, J. G. \& Gibson, C. T. Accurate thickness measurement of graphene. Nanotechnology 27, 125704, doi:10.1088/0957-

4484/27/12/125704 (2016). 


\section{Figures}
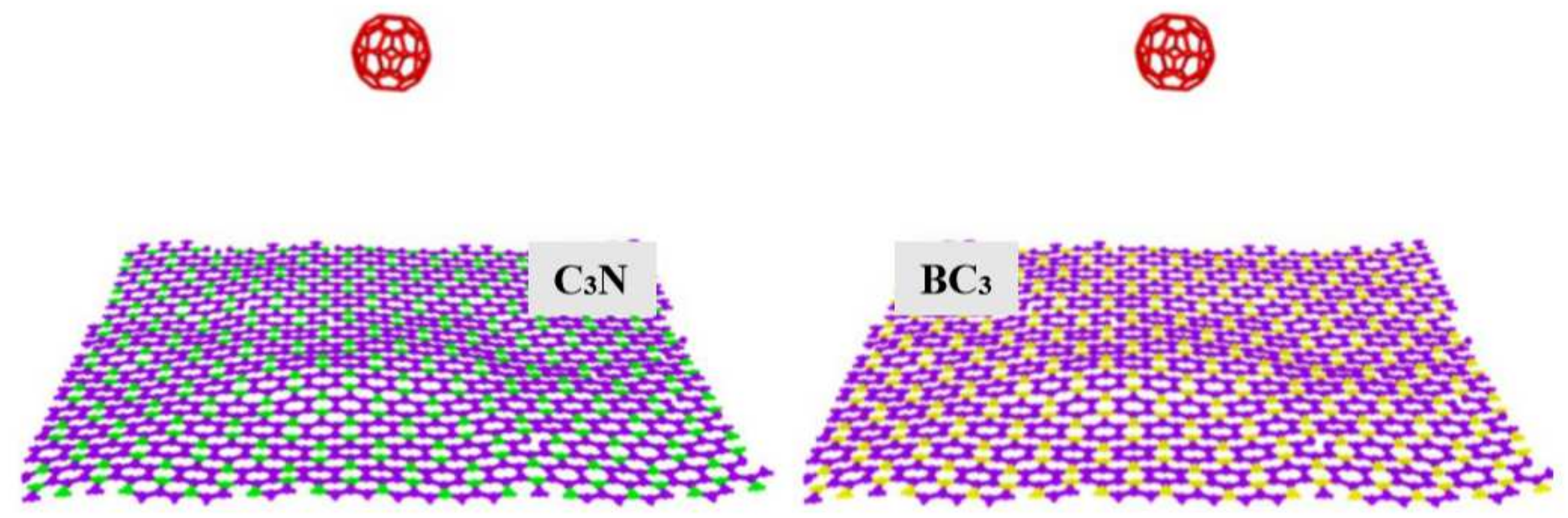

Figure 1

The C3N (left) and BC3 (right) atomic configuration with a honeycomb structure includes carbon-nitrogen and carbon-boron atoms, respectively. The red bonds show the structure of the fullerene molecule. In their ideal structures, each boron and nitrogen atom is surrounded by three carbon atoms. Carbon, nitrogen, and boron atoms are presented respectively in purple, green, and yellow.
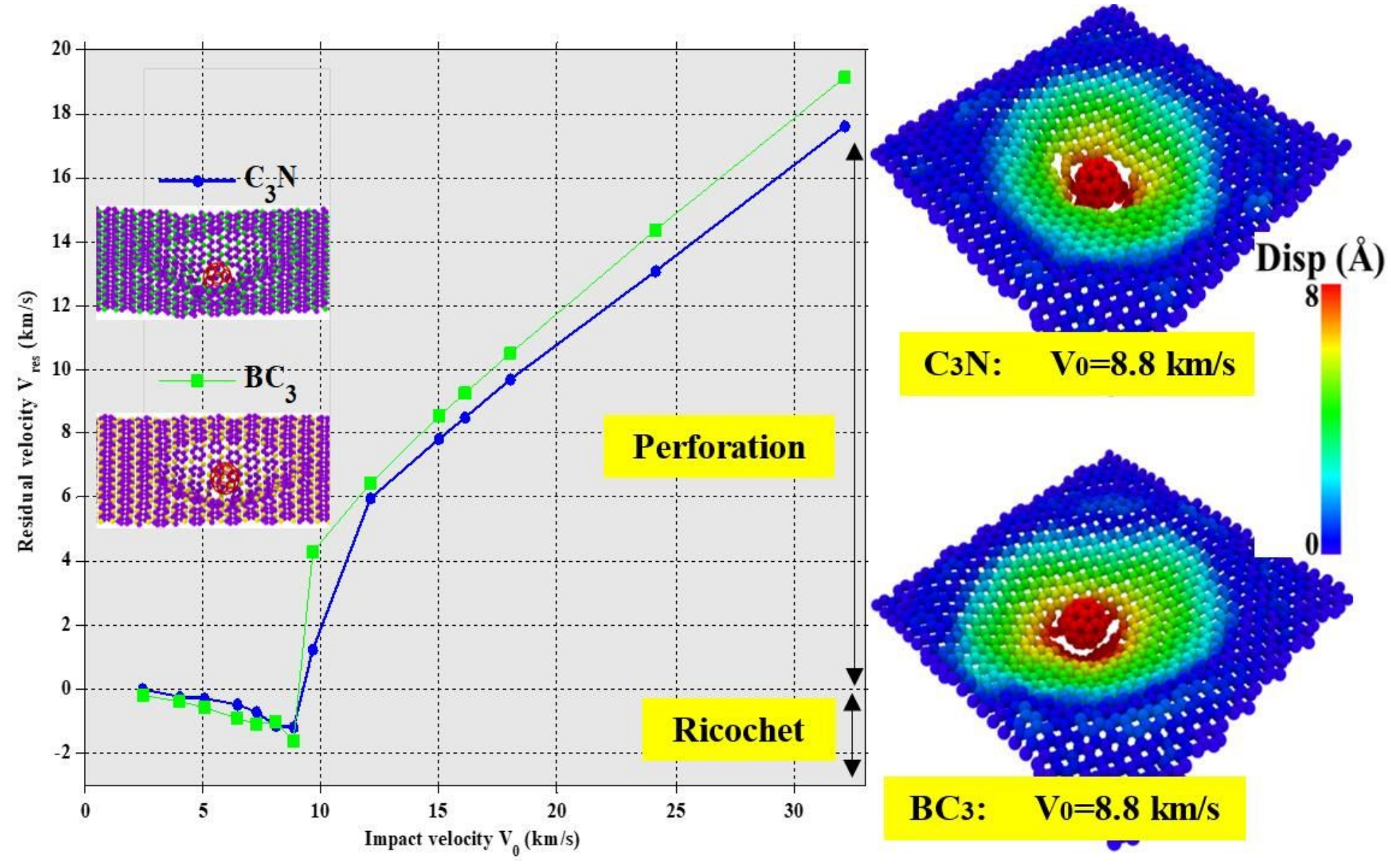

BC3: $\quad V_{0}=8.8 \mathrm{~km} / \mathrm{s}$ 
Figure 2

Left panel: Ballistic curves of single layer $\mathrm{C} 3 \mathrm{~N}$ and $\mathrm{BC}$. The residual velocity Vres is referred to the average velocity of the $\mathrm{C} 60$ atoms in the $\mathrm{Z}$ direction. Right panel: Configurations of $\mathrm{C} 3 \mathrm{~N}$ and $\mathrm{BC} 3$ at the $8.8 \mathrm{~km} / \mathrm{s}$ initial velocity of $\mathrm{C} 60$ with MD simulation. The color of each atom indicates its displacement. For visual clarity, the color bar is limited up to $8 \AA$, and the same color shows all displacements beyond this point.

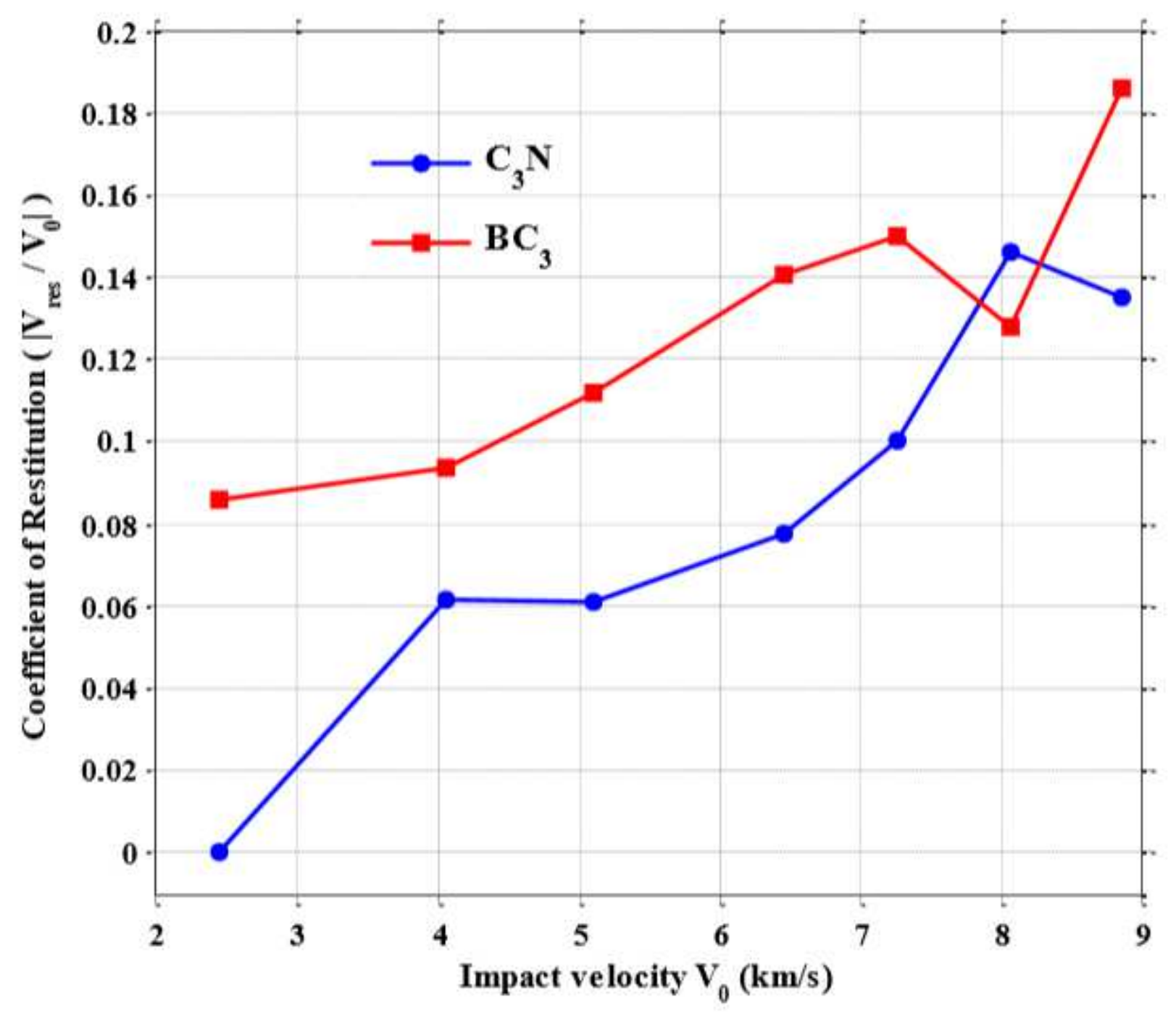

Figure 3

Coefficient of restitution for the collision of a C60 molecule along the zdirection 

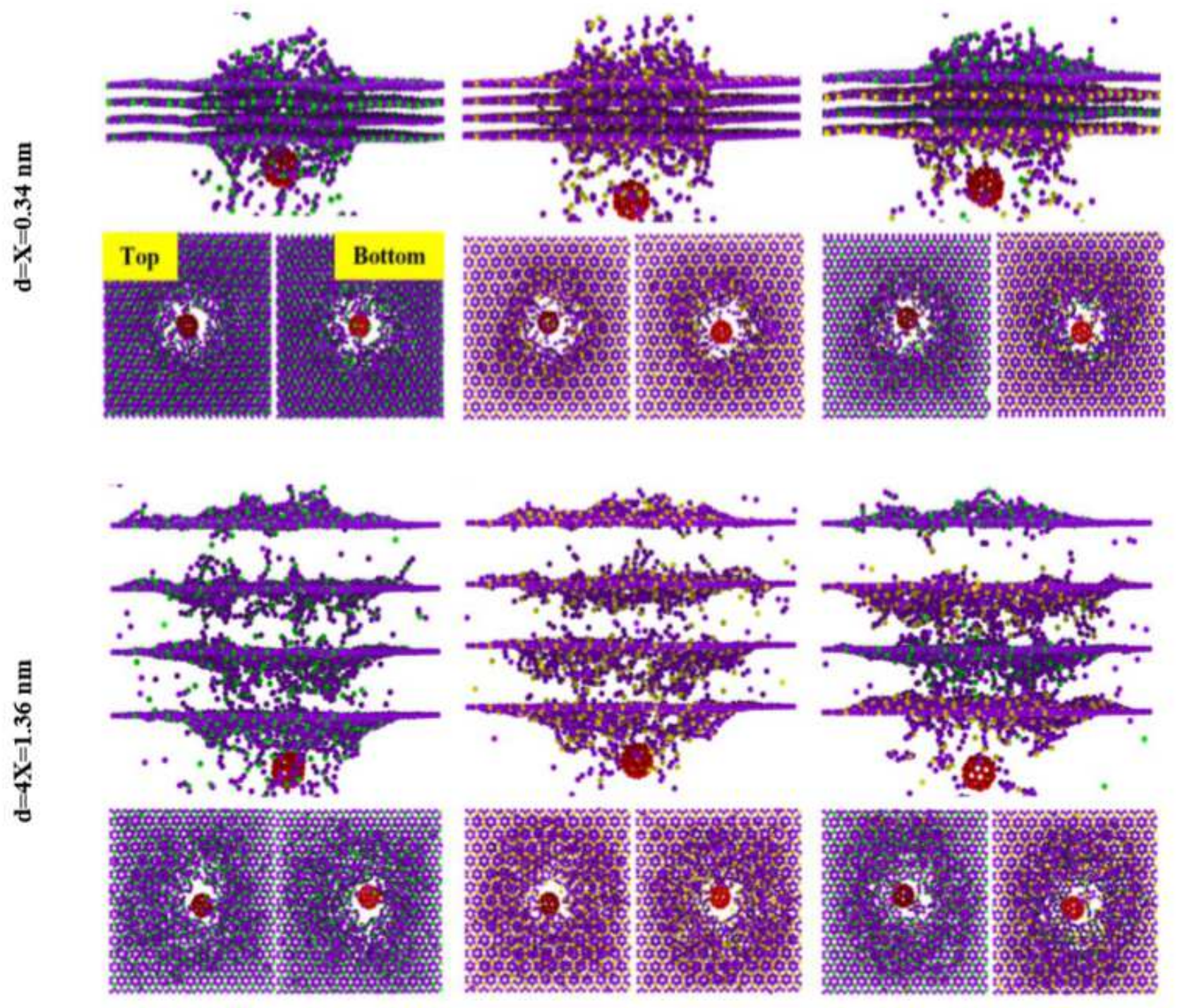

Figure 4

Image of configurations created after the C60 impact on four-layer stacks of the $\mathrm{C} 3 \mathrm{~N}, \mathrm{BC}$, and C3N-BC3 hybrid nanosheets with $\mathrm{KO}=15393.19 \mathrm{eV}$ for different layer spacing including $\mathrm{d}=\mathrm{X}=0.34$ and $\mathrm{d}=4 \mathrm{X}=1.36$ $\mathrm{nm}$. 

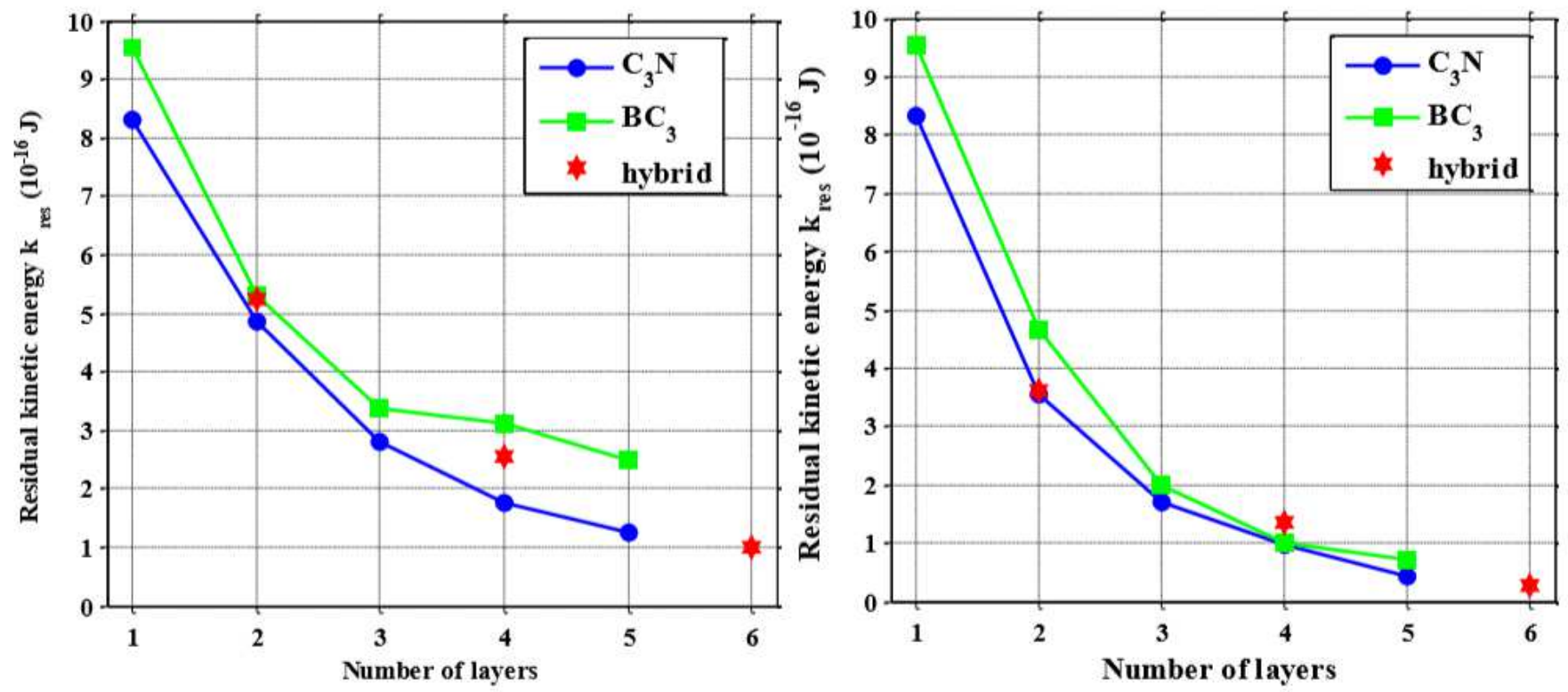

\section{Figure 5}

The number of layers effect on the residual kinetic energy Kres in the C3N, BC3, and C3N-BC3 hybrid nanosheets with $\mathrm{KO}=24.66 \times 10-16 \mathrm{~J}$ for different layer spacing including $\mathrm{d}=\mathrm{X}=0.34$ and $\mathrm{d}=4 \mathrm{X}=1.36 \mathrm{~nm}$.
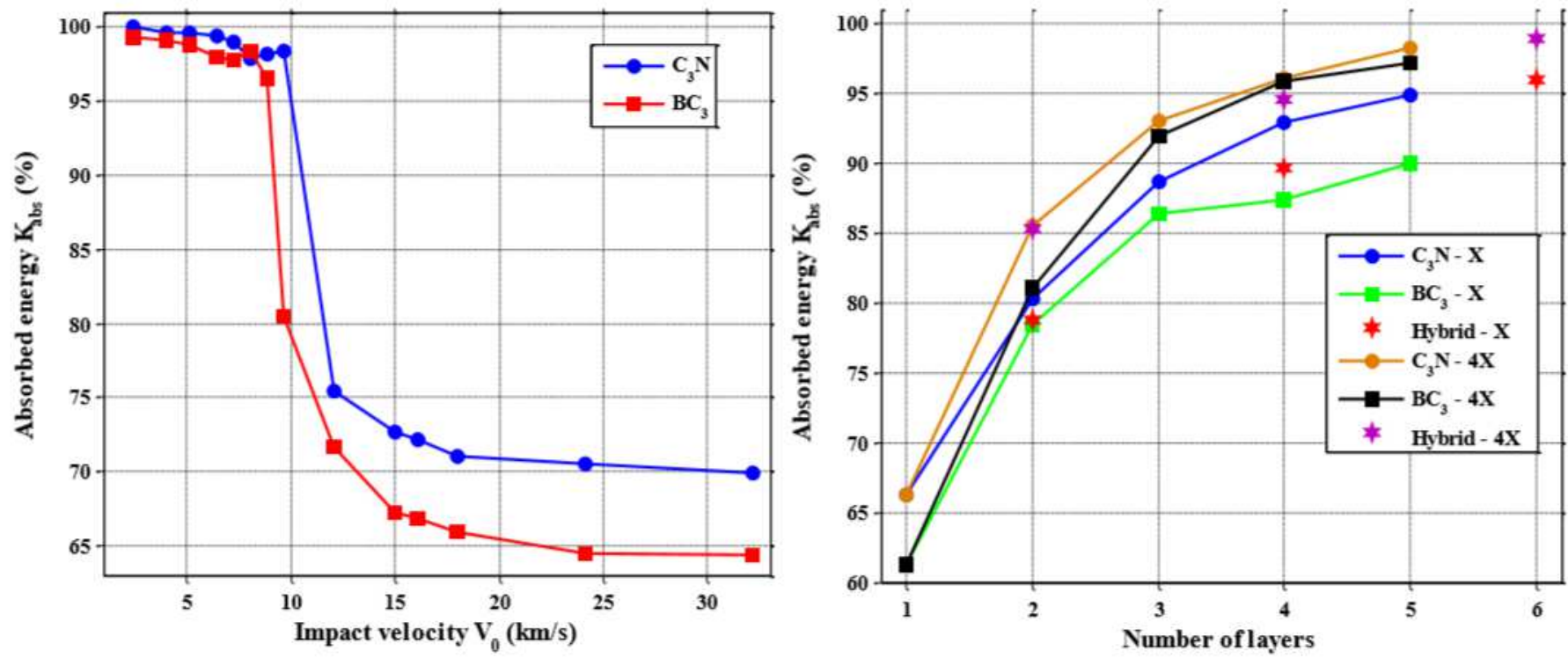

Figure 6

The energy changes adsorbed by the left sheet: increasing impact velocity and right panel: the increasing number of layers for $\mathrm{C} 3 \mathrm{~N}, \mathrm{BC} 3$, and their hybrid structures. 

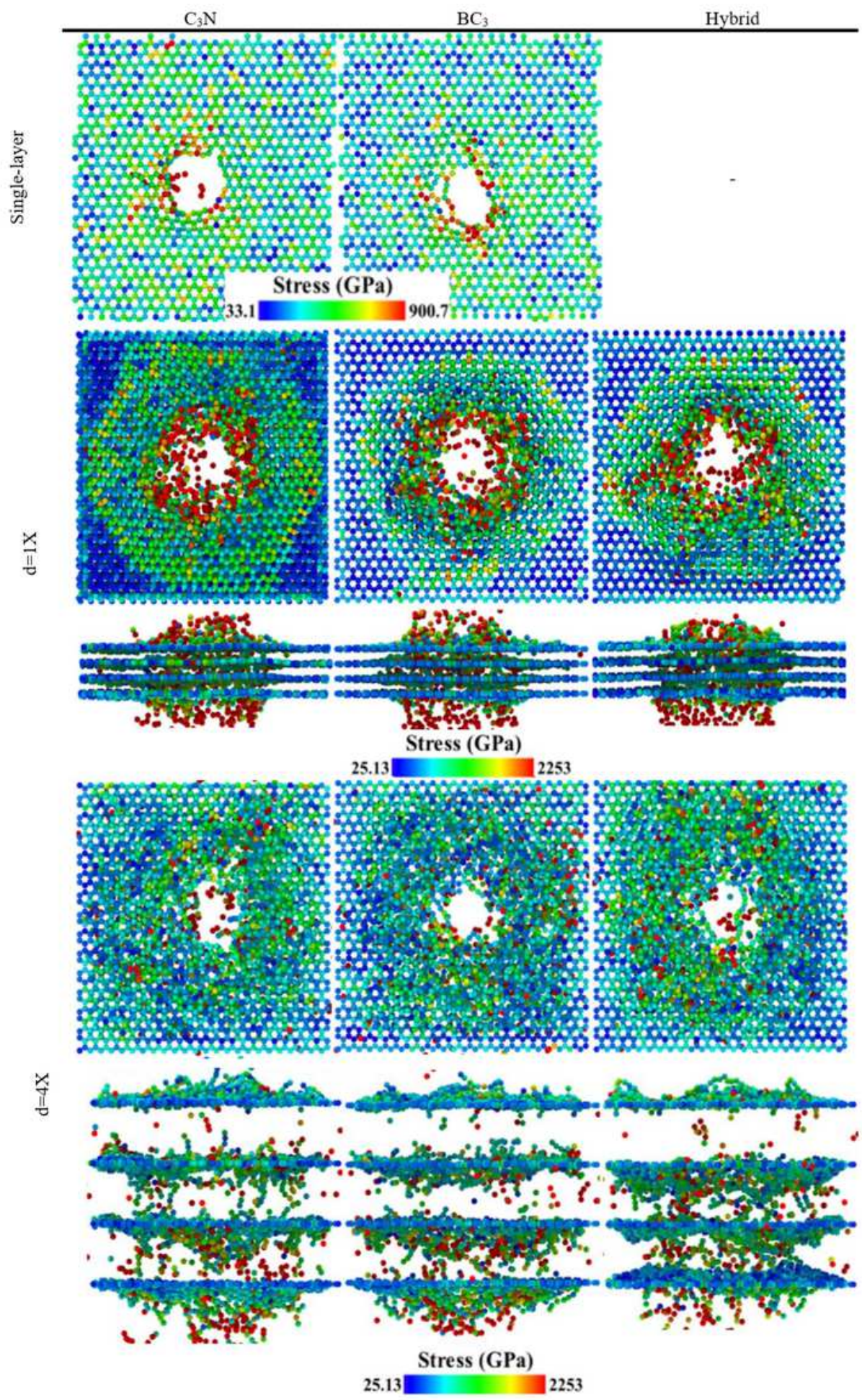

Figure 7

Von Mises stress distribution on a single layer and four-layer stacks of the C3N, BC3, and C3N-BC3 hybrid nanosheets after the $\mathrm{C} 60$ impact with $\mathrm{V} 0=64.27 \mathrm{~km} / \mathrm{s}$ for different layer spacing including $\mathrm{X}=0.34$ and $4 X=1.36 \mathrm{~nm}$. 